\title{
m1 Acetylcholine Receptor Expression is Decreased in Hippocampal CA1 region of Aged Epileptic Animals
}

\author{
Clarissa Fantin Cavarsan ${ }^{1}$, Renata Della Torre Avanzi ${ }^{1}$, Claudio Marcos Queiroz ${ }^{2}$, Gilberto \\ Fernando Xavier ${ }^{3}$, Luiz Eugênio Mello ${ }^{1}$, Luciene Covolan ${ }^{1 *}$ \\ ${ }^{1}$ Department of Physiology, Universidade Federal de São Paulo, São Paulo; Brazil \\ ${ }^{2}$ Brain Institute, Universidade Federal do Rio Grande do Norte, Natal; Brazil \\ ${ }^{3}$ Department of Physiology, Biosciences Institute, Universidade de São Paulo, São Paulo; Brazil
}

[Received June 14, 2011; Revised August 16, 2011; Accepted August 16, 2011]

\begin{abstract}
In the present study, we investigated the possible additive effects of epilepsy and aging on the expression of $\mathrm{m} 1$ muscarinic acetylcholine receptors $(\mathrm{AChR})$ in the rat hippocampus. Young ( 3 months) and Aged (20 months) male, Wistar rats were treated with pilocarpine to induce status epilepticus (SE). Immunohistochemical procedure for $\mathrm{ml}$ AChR detection was performed 2 months after pilocarpineinduced SE. In the CA1 pyramidal region $\mathrm{m1} A C h R$ staining was significantly decreased in aged epileptic animals when compared to young epileptic and aged control rats, indicating that the aging effect is worsened by the epileptic condition. However, the Nissl-stained cell analysis indicated that the number of pyramidal CA1 neurons was similarly reduced in both epileptic groups, young and aged animals. Therefore, our data suggest that the progressive reduction of $\mathrm{m} 1 \mathrm{AChR}$ expression in CA1 pyramidal cells of aged epileptic rats might bear relevance to the associated progressive cognitive impairment.
\end{abstract}

Key words: Epilepsy; m1 ACh receptor; Aging; Hippocampus; Pilocarpine; Epilepsy

Impairment of learning and memory functions in the elderly have been extensively described [1,2], as well as its worsening when associated with the epileptic condition [3, 4]. It has been proposed that alterations in cholinergic neurotransmission in the hippocampus may contribute to these cognitive deficits [5], both during natural aging $[6,7]$ and under some pathological states [8]. One of the cholinergic mechanisms proposed to explain such deficit involves $\mathrm{m} 1$ acetylcholine receptors (AChR). When the $\mathrm{m} 1 \mathrm{AChR}$ gene is knocked out in mice, the animals show variable memory impairments in hippocampal dependent tasks $[9,10]$. Considering the variable degree of learning and memory impairment of epileptic patients could be aggravated by aging, we aimed to investigate whether pilocarpine-induced seizures in aged rats would alter the expression of $\mathrm{m} 1$
AChR in CA1 pyramidal cells when compared to young and non-epileptic age-matched animals.

\section{MATERIALS AND METHODS}

\section{Animals}

Twenty-five male Wistar rats, 3 and 20 months old (250-280 g and 350-450 g, respectively), were obtained from the Center for Development of Experimental Models for Medicine and Biology-CEDEME. Animals were placed in environmentally controlled room $\left(\sim 22^{\circ} \mathrm{C}\right.$, $60 \%$ relative humidity and $12 / 12$ light/dark cycle) with free access to rat chow pellets and tap water. The protocols were approved by Animal Care and Use Ethics Committee of the Universidade Federal de São Paulo UNIFESP (Protocol number 1341/06). 

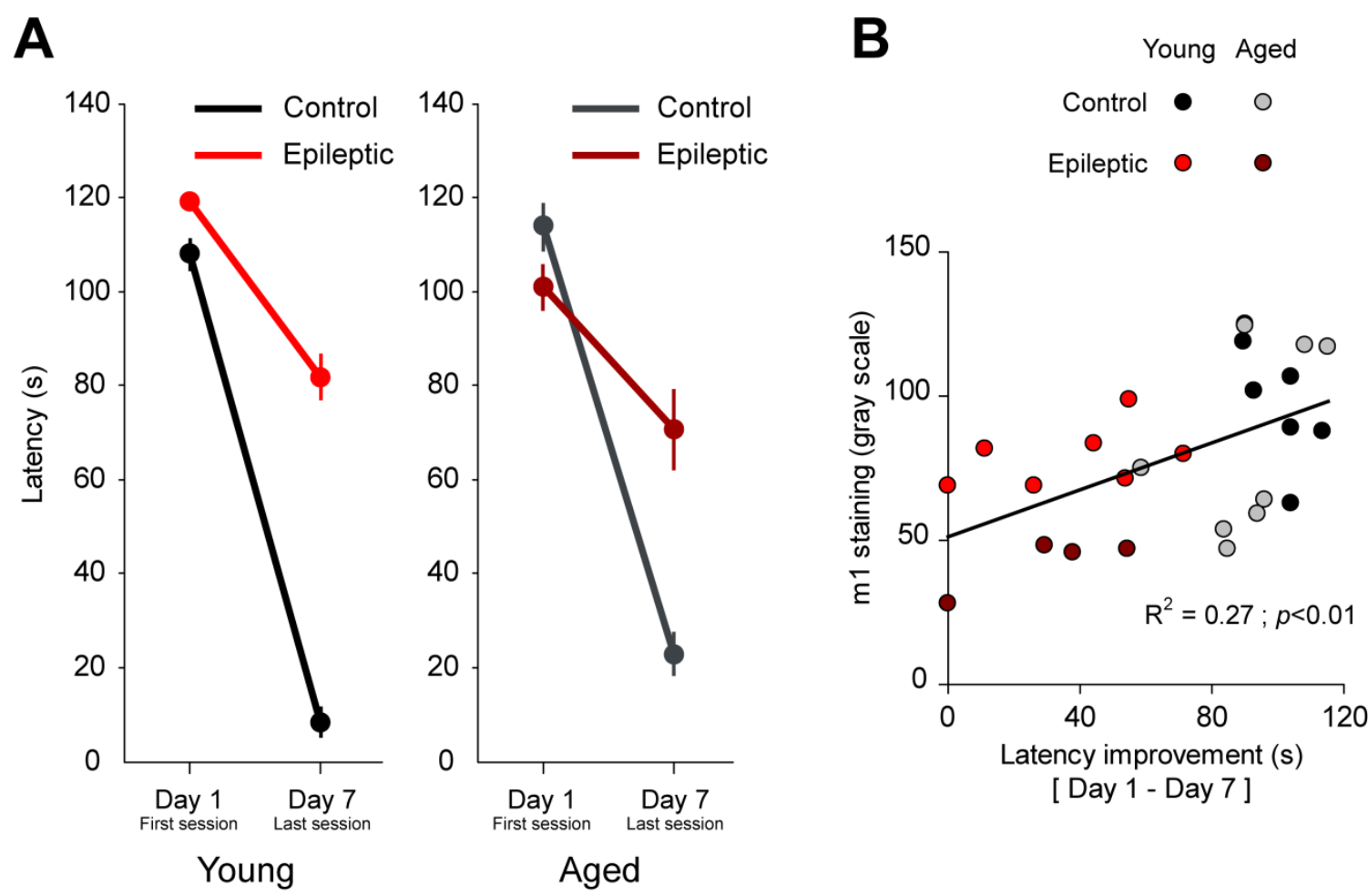

Figure 1. Water maze performance and its correlation to $\mathbf{m l}$ AChR. Graphical representation of latency reduction in the water maze task (A) and is correlation to $\mathrm{m} 1 \mathrm{AChR}$ expression (B). Statistical differences are referenced in the text.

\section{Animal model of temporal lobe epilepsy}

Epilepsy was induced by pilocarpine-evoked SE and a detailed description of the protocol used is given in elsewhere [11, 12]. Pilocarpine (i.p., Merck) was administered in young (3-mo old) and aged (20-mo old) animals, $30 \mathrm{~min}$ after methyl-scopolamine $(1 \mathrm{mg} / \mathrm{kg}$, i.p., Sigma). In order to reduce the high mortality rate after pilocarpine in aged animals, the $320 \mathrm{mg} / \mathrm{kg}$ pilocarpine dose used in young animals was reduced $50 \%$. Thus, aged-animals received $160 \mathrm{mg} / \mathrm{kg}$ of pilocarpine, assuring $80 \%$ survival rate in aged animals. Control aged-matched rats received saline injections instead of pilocarpine. After pilocarpine administration both young and aged animals were motionless for 5-10 min. Subsequently, animals displayed oro-facial movements, salivation, eye-blinking, twitching of vibrissae and yawing. These were followed by continuous limbic motor seizures with intense salivation, rearing, upper extremity clonus and falling, characterizing the SE in approximately 20-30 min after pilocarpine injection. Only those animals that showed generalized convulsions followed by status epilepticus (SE) were included in this study. Ninety minutes after SE onset, animals received thionembutal $(25 \mathrm{mg} / \mathrm{kg}$, i.p., Cristalia, Brazil), in order to attenuate SE severity and reduce the otherwise high mortality rate at this period [13]. The final number of animals for each group was: Young control ( $\mathrm{YC} ; \mathrm{N}=7$ ); Young status epilepticus (YSE; $\mathrm{N}=7$ ); Aged control $(\mathrm{AC} ; \mathrm{N}=8)$; Aged status epilepticus (ASE; $\mathrm{N}=4$ ).

Young and aged-animals did not show any difference regarding SE semiology, severity or duration, about 2-3 hours after thionembutal injection all animals from both groups had stopped body shaking. At this time on, and both groups received intensive care with $5 \%$ glucose solution ip injections on the first day (three times), followed by hand-feeding for at least 3 more days in order to increase the survival rate. Body weight decreased after SE (10-20\%), but recovered to pretreatment values after approximately 1 week. Spontaneous recurrent seizures were monitored within 15-21 days after SE and only animals presenting at least one seizure during the observational period were included in the present report. The phenotypes of spontaneous seizures were similar between young and aged animals, and the occurrences of these seizures were considered only in case of stages 4 or 5 , according to Racine scale [14]. Occurrence of seizures was not continuously monitored after epilepsy induction, animals were kept in their facilities area for two months, before the behavioral test. 


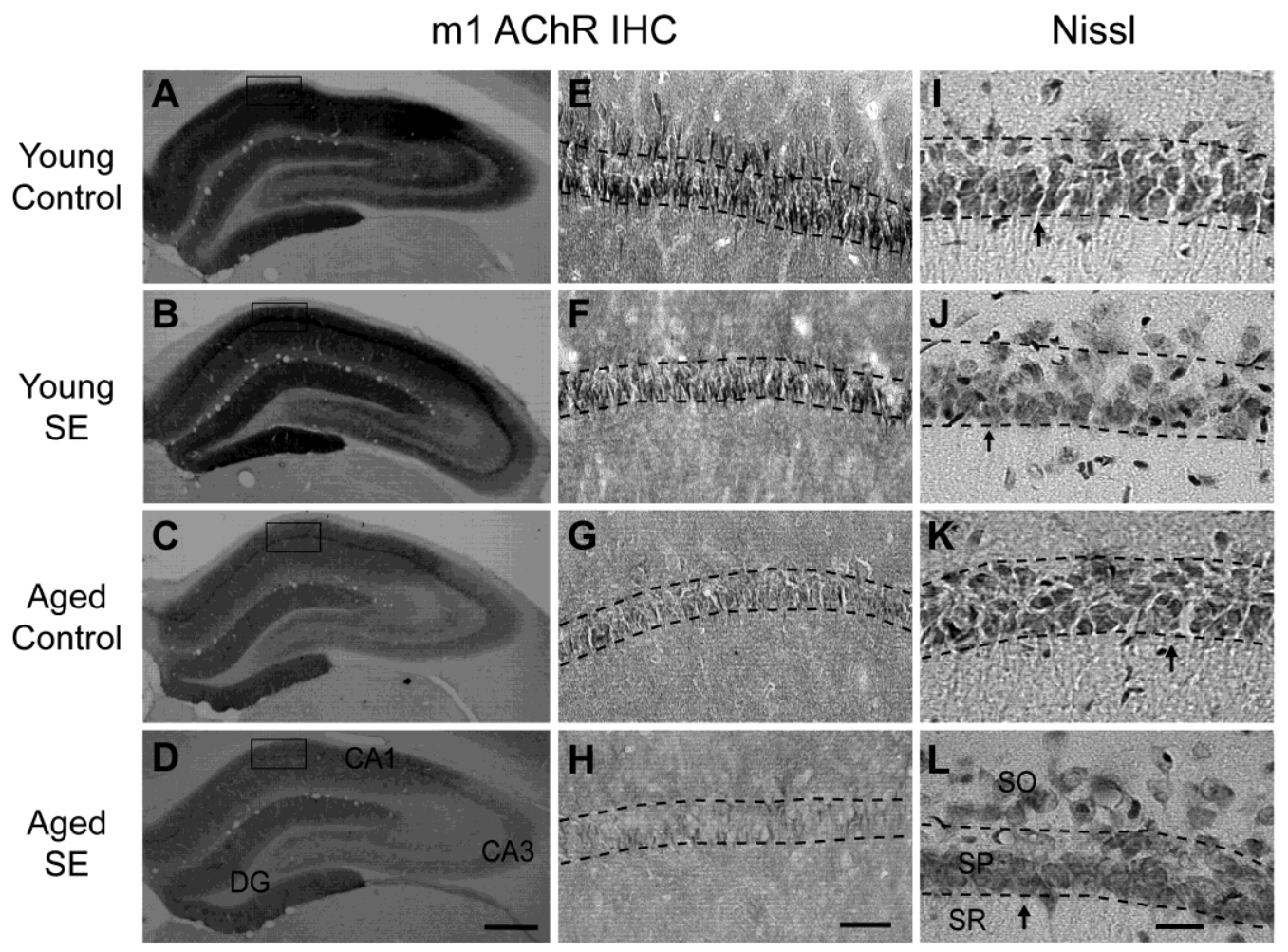

Figure 2. Photomicrographs of $\mathbf{m} 1 \mathrm{AChR}$ immunoreactivity (A-H) and Nissl-stained (I-L) sections in rat hippocampus. Representative images from Young Control group are in A, E and I; from Young SE group are in B, F and J; from Aged Control are in C, G and K; and from Aged SE group are in D, H and L. Bounded square regions in (A-D) show higher magnification of CA1 areas (E-L).Arrows and arrowheads indicate cells with intact and pyknotic morphology, respectively. Abbreviations: SO - stratum oriens; Py stratum pyramidale. Scale bar for left panel, shown in $\mathrm{D}=0.5 \mathrm{~mm}$; for central panel, shown in $\mathrm{H}=50 \mu \mathrm{m}$; and for right panel, shown in $\mathrm{L}=20 \mu \mathrm{m}$.

\section{Morris water maze}

Spatial memory performance in epileptic and control animals was evaluated using the water maze (WM) [15] two months after pilocarpine-induced SE. Details of behavioral test procedures can be found elsewhere [16].

\section{Immunohistochemistry for m1AChR}

Forty-eight hours after the completion of behavioral test, all animals were deeply anesthetized using thionembutal $(50 \mathrm{mg} / \mathrm{kg}$, i.p.) and perfused with $300 \mathrm{~mL}$ of $0.1 \mathrm{M}$ phosphate buffer (PBS; pH7.2) followed by $500 \mathrm{~mL}$ of 4\% paraformaldehyde diluted in 0.1M PBS for $15 \mathrm{~min}$. The brains were removed and kept in $30 \%$ sucrose solution diluted in 0.1M PBS for an additional $48 \mathrm{~h}$. Forty micrometer thick coronal sections covering the entire anteroposterior axis of the hippocampus were cut on cryostat and stored at $-20^{\circ} \mathrm{C}$ in anti-freezing solution (300 g sucrose and $300 \mathrm{~mL}$ ethyleneglycol in $0.1 \mathrm{M}$ PBS, 1L). For each animal, six regularly spaced (approximately $500 \mu \mathrm{m}$ apart) sections were selected and processed for m1 AChR immunohistochemistry (IHC). Brain sections from all animals were processed together to reduce possible labeling variations. Slices were incubated in $1 \% \mathrm{H}_{2} \mathrm{O}_{2}$ diluted in $0.1 \mathrm{M}$ PBS. They were then washed in PBS and incubated overnight in $\mathrm{m} 1$ muscarinic receptor polyclonal antibody $(1: 200$, raised in rabbit, Millipore, Temecula, CA) diluted in blocking buffer solution (BB) consisting of 5\% bovine fetal serum and $0.1 \%$ Triton X-100 in $0.1 \mathrm{M}$ PBS. After PBS washes, sections were incubated with a secondary antibody (1:600, goat anti-rabbit IgG, Vector Laboratories, Burlingame, CA) for $2 \mathrm{~h}$. Finally, sections were washed in PBS and incubated in standard reagent kit (Vectastain Elite ABC Kit, Vector laboratories) during $90 \mathrm{~min}$. Visualization of the peroxidase reaction was carried out using diaminobenzidine as chromogen. Sections were then washed in PBS, mounted on Superfrost glass slides (Menzel; Braunschweig, Germany), dried, dehydrated in alcohol and xylene, and finally cover-slipped with Entellan ${ }^{\circledR}$ (Merck). 
As the $\mathrm{m} 1$ AChR-immunolabeled signal did not allow the perfect outline of cell boundaries to proceed with cell counting, the signal was analyzed by optical density (OD) of DAB-stained sections. The analysis of m1 ACh immunolabeled-receptors was performed by semi-quantitative image analysis using a Nikon Eclipse E600FN light microscope. Images were captured with a Nikon DXM 1200 digital camera and analyzed using the ImageJ NIH software. The OD analysis was carried out bilaterally in hippocampal in fields including the stratum oriens and CA1 pyramidal layer. Three fields of $300 \mu \mathrm{m}^{2}$ were randomly used for analysis of CA1 area. In order to reduce any variation in the staining signal intensity among different sections and animals, the illumination was kept constant and checked regularly during images acquisitions. In addition, averages of OD signal were normalized to corpus callosum measurements of each section.

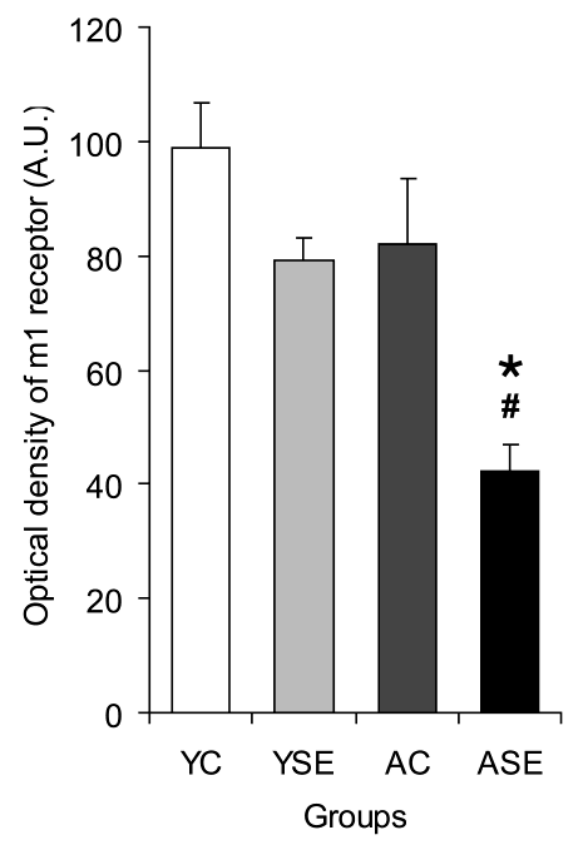

Figure 3. Optical density of $\mathrm{ml} A \mathrm{ChR}$ in the CA1 hippocampal region. Aged epileptic (ASE) rats displayed lower signal than young and aged controls (YC and AC, respectively) and young epileptic (YSE) animals. Values are expressed as mean \pm standard error of arbitrary units (A.U). * indicates differences of ASE when compared to YSE $(P<0.01)$ and ${ }^{\#}$ when compared to AC, $(P<0.05)$.

\section{Nissl staining}

In order to evaluate the severity of pilocarpine-induced brain damage at different ages, coronal brain sections from Young and Aged groups were processed for light microscopic histopathological evaluation. Six sections per animal were selected (adjacent to those used for $\mathrm{m} 1$ AChR IHC) and after Nissl-staining, the number of CA1 pyramidal neurons was quantified. The cell counting was performed using a blinded unbiased method. Six square counting frames $(200 \times 200 \mu \mathrm{m})$ were randomly placed on the pyramidal layer of CA1 area where neuronal nuclei were evaluated at one focal plane and counted using the 40x objective. Pyknotic nuclei were excluded from analysis. The values obtained are expressed as average of CA1 cells $/ 100 \mu \mathrm{m}^{2}$.

\section{Statistical analysis}

Data analysis was performed using STATISTICA Software v.8., and reported as mean \pm SEM. The WM task acquisition was directly inferred from decreases in latency to find the hidden platform along training. These scores were subjected to repeated-measures analyses of variance (ANOVA). Comparisons among multiple groups were performed using the two-way ANOVA followed by the Newman-Keuls test. Pearson's correlation coefficient $(r)$ was derived to investigate the relationship between latency decreases and $\mathrm{ml} A \mathrm{ACh}$ labeling. The level of statistical significance was $P<0.05$.

\section{RESULTS}

\section{Behavioral test}

Despite the age and experimental condition, all animals were able to improve their performance in finding the hidden platform during the 7-days WM exposure. Learning improvement was compared by the difference between the last and (Day 7) the first day test (Day 1). Nevertheless, the latency reduction was significantly smaller in epileptic animals compared to their agematched controls $(P<0.001$; Figure 1A). Differences in the latency to find the platform were calculated and a positive correlation between this index and the $\mathrm{m} 1$ staining was observed $(P<0.001$; Figure 1B).

\section{m1 AChR expression}

m1 AChR immunoreactivity was enriched in CA1 as compared to $\mathrm{CA} 2$ and $\mathrm{CA} 3$ (Figure 2), present throughout Ammon's horn in the soma of pyramidal neurons and their proximal apical and basal dendrites in stratum radiatum and stratum oriens, respectively. Dendrites in the molecular layer from dentate gyrus but not the granular cell layer were also $\mathrm{m} 1 \mathrm{mAChR}$ immunoreactive (Figures 2A, B, C and D).

As the $\mathrm{m} 1 \mathrm{AChR}$ staining was more robust in CA1 hippocampal region, possible changes in the $\mathrm{m} 1 \mathrm{AChR}$ staining levels were investigated between young and aged, epileptic and control animals in this area. The two- 
way ANOVA analysis indicated that the $\mathrm{m} 1 \mathrm{AChR}$ immunorreactivity was affected by age $\left(\mathrm{F}_{[1,22]}=8.77\right.$; $P<0.01)$ and epilepsy $\left(\mathrm{F}_{[1,22]}=10.93 ; P<0.005\right)$, although no interaction between both factors were detected $\left(\mathrm{F}_{[1,22]}=1.26 ; P=0.273\right)$. The optical densitometry in the CA1 pyramidal region revealed significant decreases in m1 AChR staining of ASE animals (Figure 2D and $\mathrm{H}$ ) when compared to YSE (Figure $2 \mathrm{~B}$ and $\mathrm{F}$ ) and $\mathrm{AC}$ (Figures $2 \mathrm{C}$ and $\mathrm{G} ; P<0.05$, Figure 3 ).

\section{Pyramidal cell counting}

As previously described by our group and others, a notable feature of this animal model is the extensive loss of CA1 pyramidal neurons in the hippocampus [17, 18]. Similarly, in the present study, the two-way analysis indicated that only the epileptic condition has effect on the CA1 pyramidal cell number $\left(\mathrm{F}_{[1,21]}=23.85 ; P<0.001\right)$. Epileptic young (Figure 2J) and aged (Figure 2L) animals had decreased number of pyramidal cells in CA1 area as compared to its control groups $(P<0.05$, Figure 4; Figures $2 \mathrm{I}$ and $\mathrm{K}$ ). However, both young and aged epileptic groups displayed similar reduction in the number of cells, associated to dispersion of CA1 pyramidal cell layer (Figure 1J 2J and L).

\section{DISCUSSION}

The current data demonstrate that CA1 pyramidal region of hippocampus has a significant decrease in $\mathrm{m} 1 \mathrm{AChR}$ staining in ASE animals when compared to YSE and AC groups. This indicates that aging and epilepsy only affect the $\mathrm{m} 1 \mathrm{AChR}$ density in CA1 hippocampal region when these conditions appear together.

$\mathrm{m} 1 \mathrm{AChR}$ plays a critical role in hippocampal function [19-21]. The CA1 pyramidal layer receives robust cholinergic inputs [22] and synaptically released acetylcholine binds to $\mathrm{m} 1 \mathrm{AChR}$ expressed in pyramidal neurons [21]. m1 ACHR signaling enhances NMDAmediated responses [23] and activates ryanodine receptors [23], both resulting in increased intracellular calcium levels. These calcium waves traveled from the apical dendrites toward the soma and were followed by long-term enhancement of AMPA- [24] and NMDAmediated transmission [25] adding flexibility to the cellular machinery of learning and memory in the hippocampus. These findings bring some light to the current results and may explain why aged epileptic rats have more severe learning and memory impairments than do age-matched control rats [26]. This suggests that reductions of $\mathrm{ml} \mathrm{AChR}$ at $\mathrm{CA} 1$ pyramidal cells of epileptic rats may underlie the reduction of long-term potentiation present among aged animals. Interestingly some of the above mentioned studies were conducted in very young animals (14-16 days), thus whether these mechanisms are also present among aged animals remains to be elucidated.

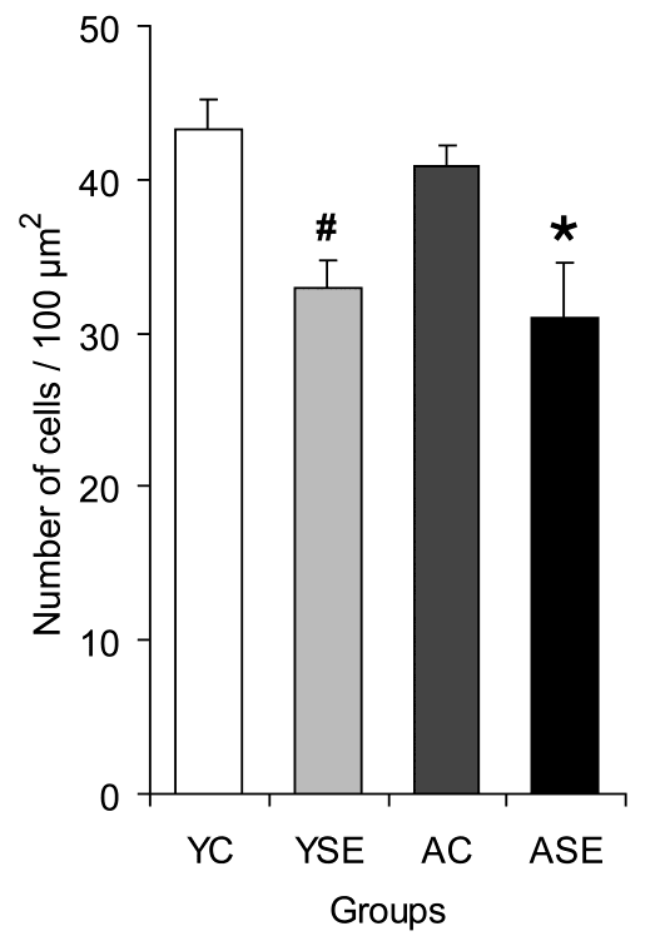

Figure 4. Graphical representation of the number of CA1 pyramidal cells in young control (YC), young SE (YSE), aged control (AC) and aged epileptic (ASE) animals. Epileptic animals displayed less CA1 pyramidal cells when compared to their respective controls. Values are expressed as mean \pm standard error. Abbreviations are the same as used in the Figure 2. Symbol \# indicates the difference between YSE and YC $(P<0.05)$; and symbol ${ }^{*}$ indicates the difference between ASE and AC $(P<0.05)$.

On the other hand, recently it was also demonstrated that $\mathrm{m} 1 \mathrm{ACh}$ receptors contributes to presynaptic inhibition of glutamatergic transmission from Schaffer collaterals on CA1 pyramidal cells. Kremin and colleagues demonstrated that the absence of $\mathrm{ml} \mathrm{AChR}$ substantially decreases the presynaptic inhibition at the Schaffer collaterals [20]. This indicates that muscarinic cholinergic modulation of long term hippocampal plasticity is very controversial and diverse. Thus, acting by means of increasing AMPA and NMDA receptor activation, or reducing presynaptic inhibition of glutamatergic release from Schaffer collaterals on CA1 pyramidal cells, may be two mechanisms through which $\mathrm{m} 1 \mathrm{AChR}$ reduction might be related to poor learning and memory ability in aged epileptic animals. 
The current results demonstrated that the number of CA1 pyramidal cells is reduced in epileptic versus agematched control groups, independent of the animal's age at time of SE onset. Thus, among young animals, the epileptic condition has no effect on the m1AChR density, possibly indicating a compensatory $\mathrm{m} 1$ receptor up regulation. As normal aging is accompanied by reduction of m1AChR in pyramidal cells [27], we speculate that the remaining CA1 pyramidal cells after status epilepticus, in aged animals, are not able to proceed similarly. Our findings suggest that functional decline when aging and epilepsy are associated, might not primarily result from cell loss, but other mechanisms which includes impairment in intracellular signaling among others [28].

Finally, is important to consider that possible differences in the status epilepticus duration and severity can't be ruled out, because in the present study, no electrographical recordings were performed during induction. These possibilities should be taken into consideration in future studies.

Taking together data from $\mathrm{m} 1 \mathrm{AChR}$ expression and Nissl counting of CA1 pyramidal cells, we observed that decreases of $\mathrm{m} 1 \mathrm{AChR}$ expression in ASE group is not solely due to the epileptic condition or to aging in isolation, but rather to the association of both factors.

\section{Acknowledgments}

The authors are grateful to the research support provided by FAPESP (2006/60256-5), Ivone de Paulo and Clivandir Severino da Silva, from Department of Physiology in Universidade Federal de Sao Paulo, for their excellent technical assistance.

\section{References}

[1] Eppinger B, Herbert M and Kray J (2010). We remember the good things: Age differences in learning and memory. Neurobiol Learn Mem, 93: 515-521

[2] Gutchess A and Park D (2009). Effects of Aging on Associative Memory for Related and Unrelated Pictures. Eur J Cogn Psychol., 21: 235-254

[3] Helmstaedter C and Elger C (1996). Cognitive consequences of two-thirds anterior temporal lobectomy on verbal memory in 144 patients: a three-month followup study. Epilepsia, 37: 171-180

[4] Tuchscherer V, Seidenberg M, Pulsipher D, Lancaster M, Guidotti L and Hermann B (2010). Extrahippocampal integrity in temporal lobe epilepsy and cognition: thalamus and executive functioning. Epilepsy Behav, 17: 478-482

[5] Pereira H, Benassi S and Mello L (2005). Plastic changes and disease-modifying effects of scopolamine in the pilocarpine model of epilepsy in rats. Epilepsia, 46: 118124

[6] Drachman D and Leavitt J (1974). Human memory and the cholinergic system. A relationship to aging? Arch Neurol., 30: 113-121

[7] Flicker C, Dean R, Bartus R, Ferris S and Crook T (1985). Animal and human memory dysfunctions associated with aging, cholinergic lesions, and senile dementia. Ann N Y Acad Sci, 444: 515-517

[8] Bartus R (2000). On neurodegenerative diseases, models, and treatment strategies: lessons learned and lessons forgotten a generation following the cholinergic hypothesis. Exp Neurol., 163: 495-529

[9] Anagnostaras S, Murphy G, Hamilton S, Mitchell S, Rahnama N, Nathanson N and Silva A (2003). Selective cognitive dysfunction in acetylcholine M1 muscarinic receptor mutant mice. Nat Neurosci., 6: 51-58

[10] Miyakawa T, Yamada M, Duttaroy A and Wess J (2001). Hyperactivity and intact hippocampus-dependent learning in mice lacking the M1 muscarinic acetylcholine receptor. J Neurosci., 21: 5239-5250

[11] Covolan L and Mello L (2006). Assessment of the progressive nature of cell damage in the pilocarpine model of epilepsy. Braz J Med Biol Res., 39: 915-924

[12] Covolan L, Smith R and Mello L (2000). Ultrastructural identification of dentate granule cell death from pilocarpine-induced seizures. Epilepsy Res, 41: 9-21

[13] Mello L, Cavalheiro E, Tan A, Kupfer W, Pretorius J, Babb T and Finch D (1993). Circuit mechanisms of seizures in the pilocarpine model of chronic epilepsy: cell loss and mossy fiber sprouting. Epilepsia, 34: 985-995

[14] Racine R (1972). Modification of seizure activity by electrical stimulation. II. Motor seizure. Electroencephalogr Clin Neurophysiol., 32: 281-294

[15] Morris R, Garrud P, Rawlins J and O'Keefe J (1982). Place navigation impaired in rats with hippocampal lesions. Nature, 297: 681-683

[16] Avanzi R, Cavarsan C, Santos Jr J, Hamani C, Mello L and Covolan L (2010). Basal dendrites are present in newly born dentate granule cells of young but not aged pilocarpine-treated chronic epileptic rats. Neuroscience, 170: 687-691

[17] Lehmann T, Gabriel S, Kovacs R, Eilers A, Kivi A, Schulze K, Lanksch W, Meencke $\mathrm{H}$ and Heinemann U (2000). Alterations of neuronal connectivity in area CA1 of hippocampal slices from temporal lobe epilepsy patients and from pilocarpine-treated epileptic rats. Epilepsia, 41: S190-194

[18] Mello L and Covolan L (1996). Spontaneous seizures preferentially injure interneurons in the pilocarpine model of chronic spontaneous seizures. Epilepsy Res., 26: $123-129$

[19] Balakrishnan S, Mathew J and Paulose C (2010). Cholinergic and glutamergic receptor functional regulation in long-term, low dose somatotropin and insulin treatment to ageing rats: rejuvenation of brain function. Mol Cell Endocrinol., 314: 23-30

[20] Kremin T, Gerber D, Giocomo L, Huang S, Tonegawa S and Hasselmo M (2006). Muscarinic suppression in 
stratum radiatum of CA1 shows dependence on presynaptic $\mathrm{M} 1$ receptors and is not dependent on effects at GABA(B) receptors. Neurobiol Learn Mem., 85: 153163

[21] Levey A, Edmunds S, Koliatsos V, Wiley R and Heilman C (1995). Expression of m1-m4 muscarinic acetylcholine receptor proteins in rat hippocampus and regulation by cholinergic innervation. J Neurosci., 15: 4077-4092

[22] Frotscher $M$ and Léránth C (1985). Cholinergic innervation of the rat hippocampus as revealed by choline acetyltransferase immunocytochemistry: a combined light and electron microscopic study. J Comp Neurol., 239: 237-246

[23] Harvey J, Balasubramaniam $R$ and Collingridge $G$ (1993). Carbachol can potentiate N-methyl-D-aspartate responses in the rat hippocampus by a staurosporine and thapsigargin-insensitive mechanism. Neurosci Lett., 162: 165-168

[24] Fernández de Sevilla D, Núñez A, Borde M, Malinow R and Buño W (2008). Cholinergic-mediated IP3-receptor activation induces long-lasting synaptic enhancement in CA1 pyramidal neurons. J Neurosci., 28: 1469-1478

[25] Fernández de Sevilla D and Buño W (2010). The muscarinic long-term enhancement of NMDA and AMPA receptor-mediated transmission at Schaffer collateral synapses develop through different intracellular mechanisms. J Neurosci., 30: 11032-11042

[26] Covolan L, Urini A, Avanzi R, Cavarsan C, Santos Jr J and Mello L (2009) Cholinergic inputs to hippocampus is reduced in aged animals after pilocarpine-induced seizures. In Society for Neuroscience Meeting p. 17572, Chicago

[27] Tayebati S, Amenta F, El-Assouad D and Zaccheo D (2002). Muscarinic cholinergic receptor subtypes in the hippocampus of aged rats. Mech Ageing Dev., 123: 521528

[28] Tandon P, Mundy W, Ali S, Nanry K, Rogers B and Tilson H (1991). Age-dependent changes in receptorstimulated phosphoinositide turnover in the rat hippocampus. Pharmacol Biochem Behav., 38: 861-867 